ارزيابى وضعيت تغذيهاى باغهاى ليموترش در هرمز گان با روش تشخيص جندگانه عناصر غذايى

يعقوب حسينى "، جهانشاه صالح' و محمدرضا جاكر الحسينى

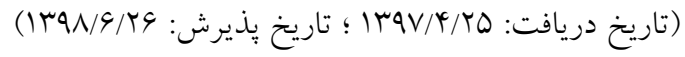

جكيده

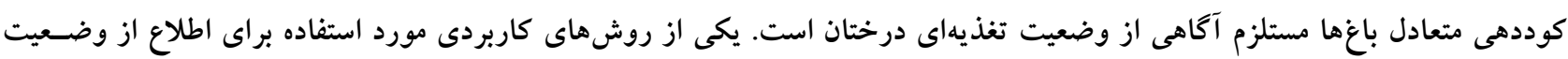

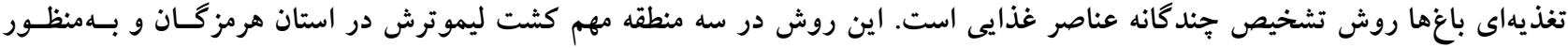

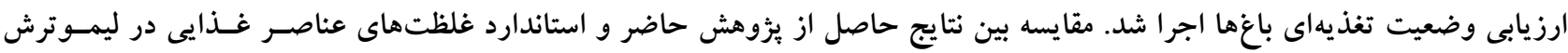

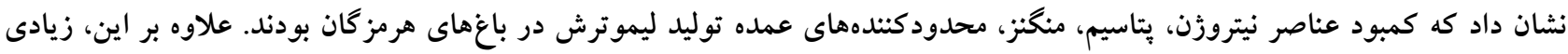

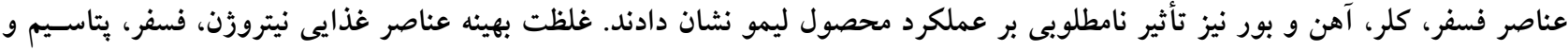

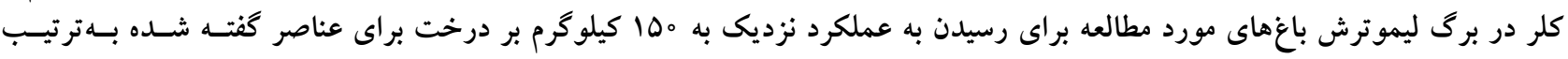

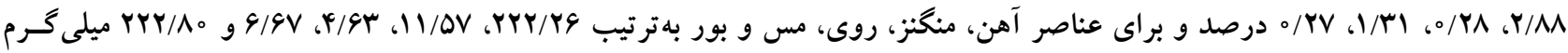

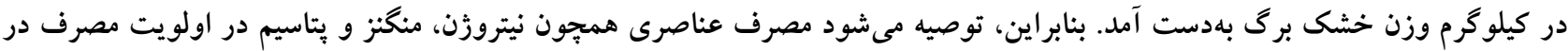

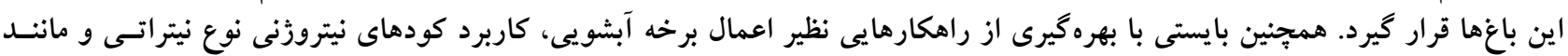

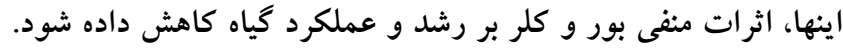

وازههاى كليدى: تعادل تغذيهاى، روش CND، عملكرد، مركبات

ا. عضو هيأت علمى بخش تحقيقات خاك و آب، مركز تحقيقات و آموزش كشاورزى و منابع طبيعى استان هرمز كان، سازمان تحقيقات، آموزش

$$
\text { و ترويج كشاورزى، بندرعباس، ايران. }
$$

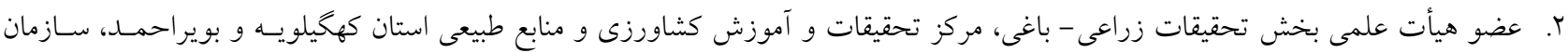

$$
\text { تحقيقات، آموزش و ترويج كشاورزى، ياسوج، ايران. }
$$

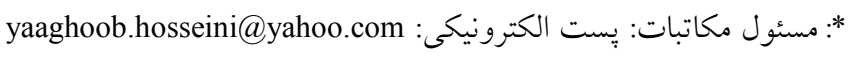


است كه علاوه بر رعايت شدن زمان نمونسهــــدارى و برداشـت عضو مناسب نمونهبـردارى، از روشهـاى صسحيح و اسـتاندارد

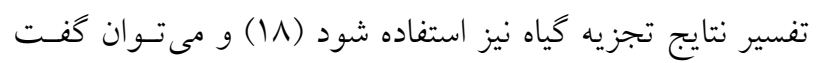
ارزش كاربردى تجزيه كياه در شناخت وضعيت تغذيسهاى كيـاه

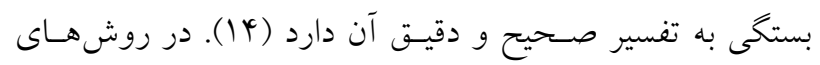

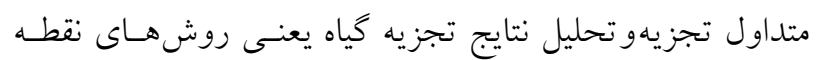
بحر انى و دامنه كفايت فقط حد كمبود يا سميت براى هر عنصر بلهور جداكانه تعيين شده، ليكن تعادل بين عناصـر غـذايى كـهـ

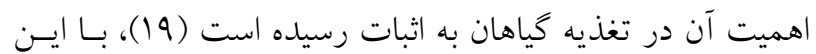
روشها ارزيابى نمىشوند (11). تفسير نتايج تجزيه كياه بهدليل

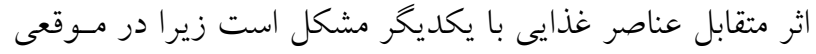

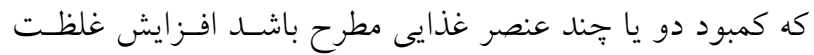
يك عنصر باعث تغيير غلظت بحرانى عنصر ديخر مى نود (19). بههمين دليل روشهاى غلظـت بحرانسى و دامنـه كفايست داراى

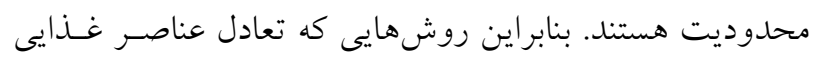
را درنظر مى گيرند، روشهاى بهتـرى هستـند (11). روشهـاى هـائ

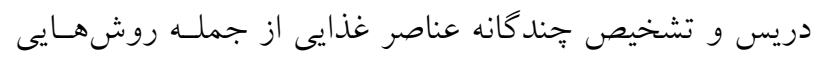

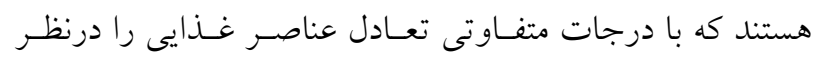
مى گيرند. روش دريس سامانه بهنسبت جـامعى اسـت كـه كليـه

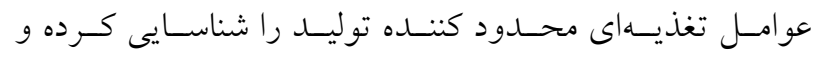

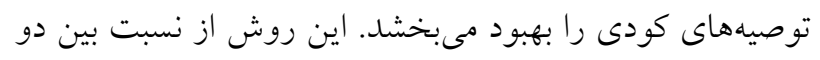

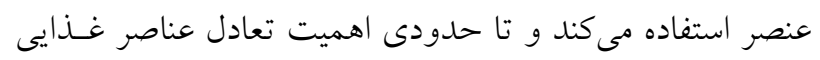

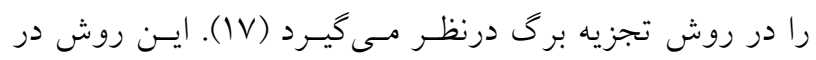

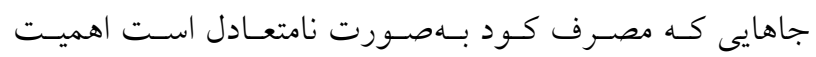

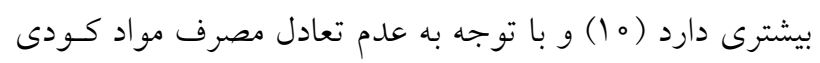

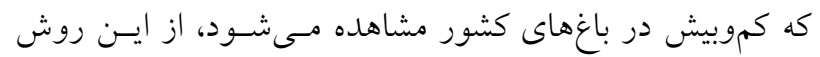

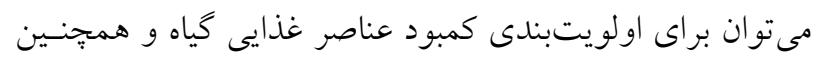

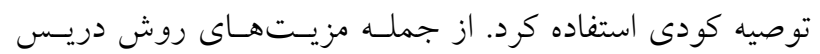
مىتوان به تعيين وضعيت تعادل عناصر غذايى، تعيسين اولويـتـت فيت

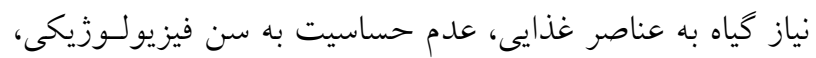

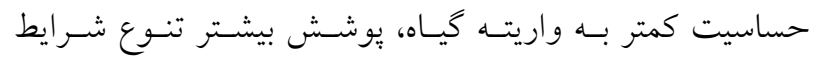

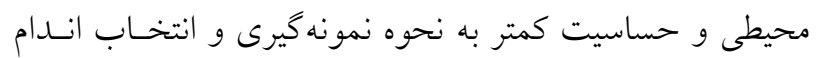

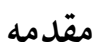

در شر ايط كاملاً مساعد مقدار توليد در كَاهان، مىتواند در حـــــ

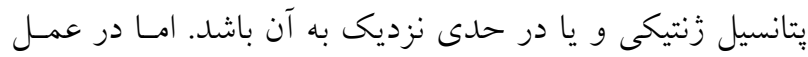

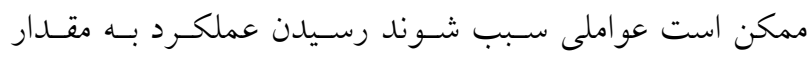
ظرفيت زنتيكى تحقق بيدا نكند. يكى از اين عوامل كمبود و يـا

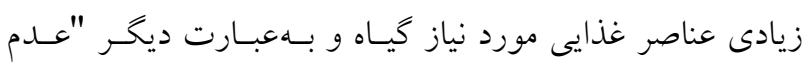

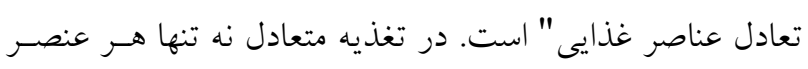
بايد به اندازه كافى در دسترس گياه قرار بخيـرد، بلكسه تعـادل و

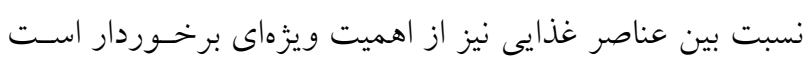

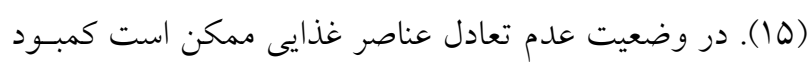

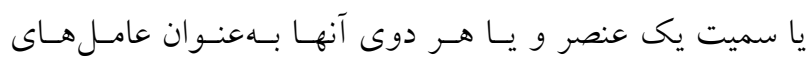

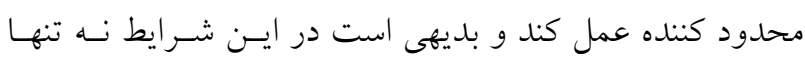

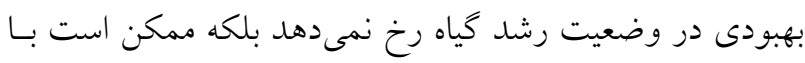

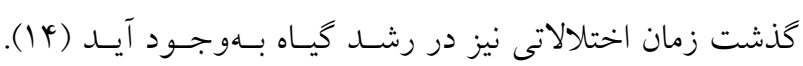

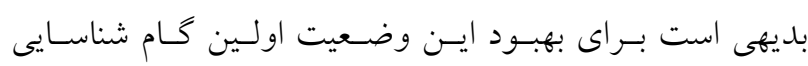

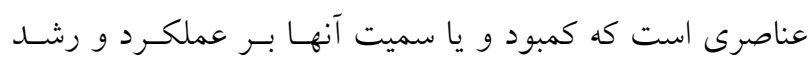

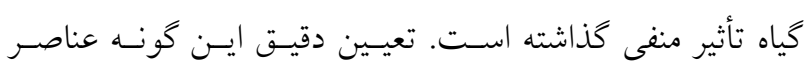

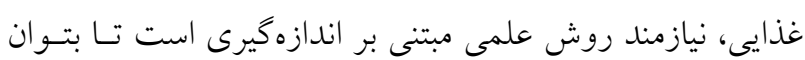

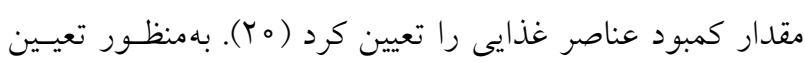

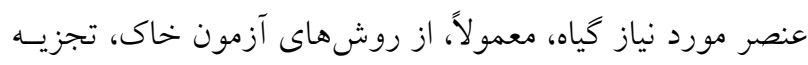

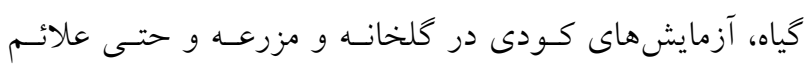

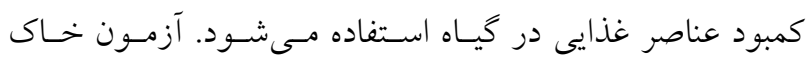
ابزارى است كه براى تعيين فرمولاسـيون كودهـاى بايسه بــهـار

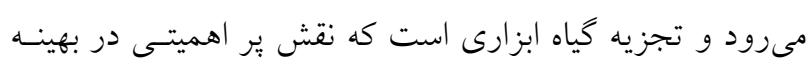

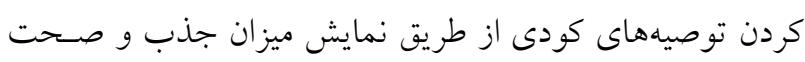
آزمون خاك دارد (N). در سنجش وضعيت تغذيه كيـاه، تجزيـه

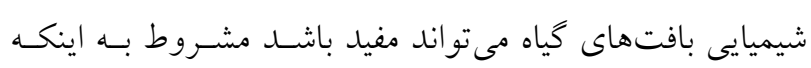

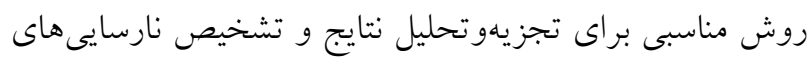

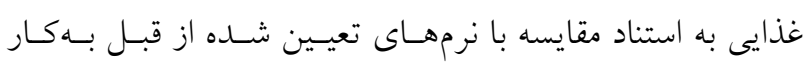

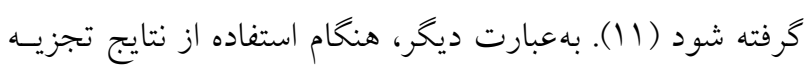

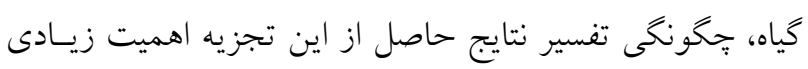

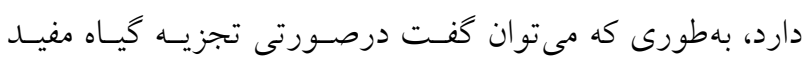


حل معادلات تابع تجمعى درجه سه مربوط به ده عنصر غـذايى

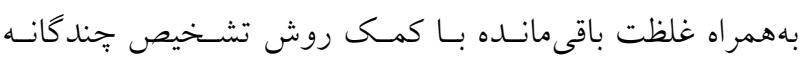

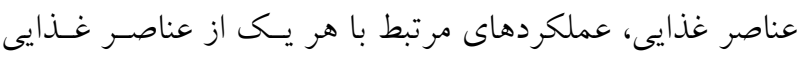

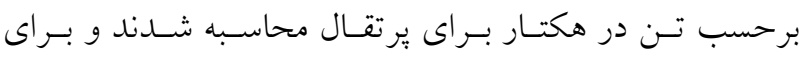

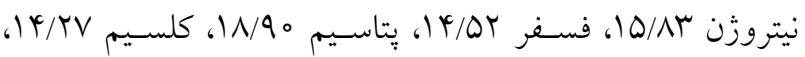

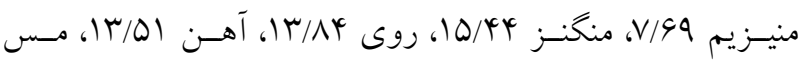

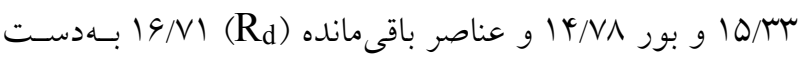

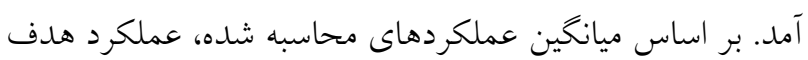

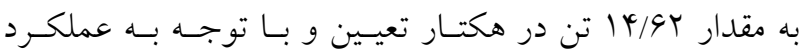

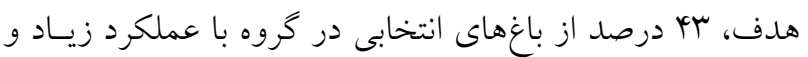

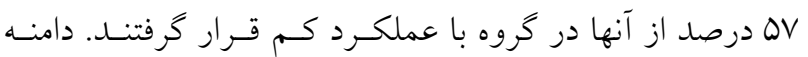

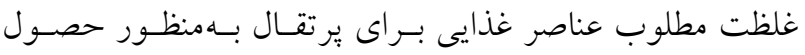

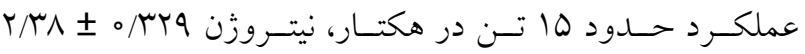

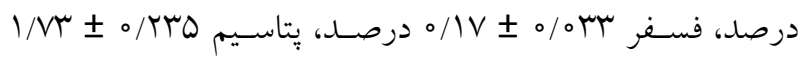

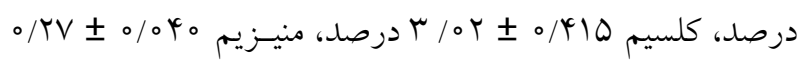
درصـد، منخنـز

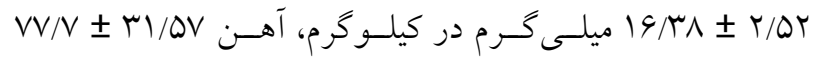
ميلى گرم در كيلو گرم، مس ل

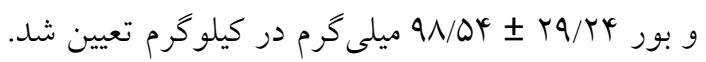
در باغهاى هلو در استان كلستان ترتيب نيـاز بـهـ عناصـر

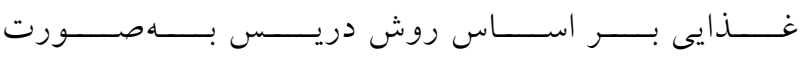

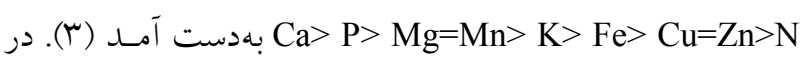

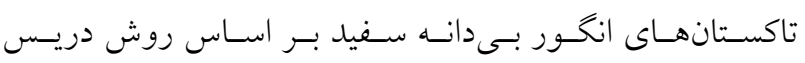
منفى ترين شاخص در بين عناصر يرنياز براى عنصر منيزيم و در

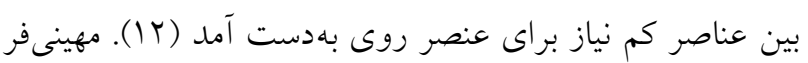

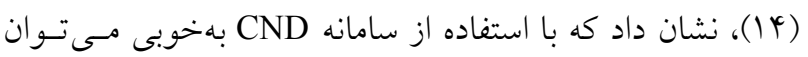

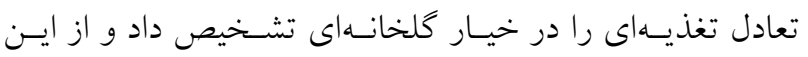

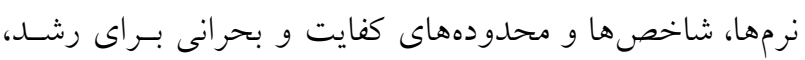

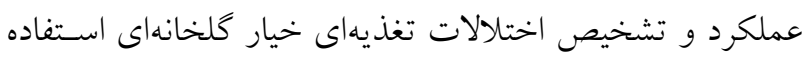

مقدار ميـانخين عملكــد در هكتـار ليمـوترش در بـاغهـاى

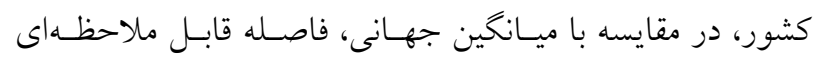

مورد مطالعه اشاره كـرد (11). بـا وجـود ايسن روش تشـخيص

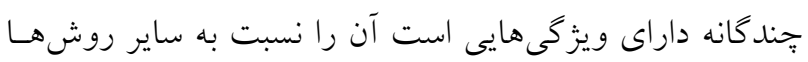

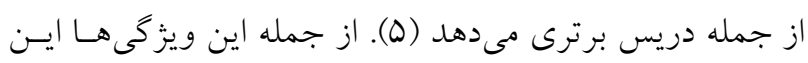

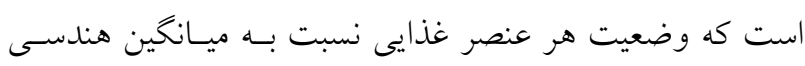

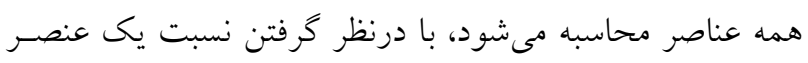

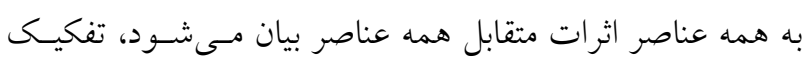

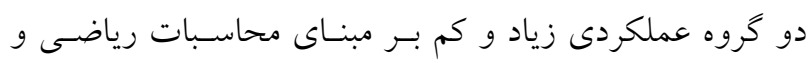

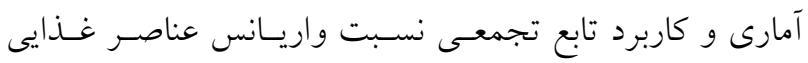
است، اين روش نسبت به ساير روشها دقت بيشـترى دارد، بـهـ

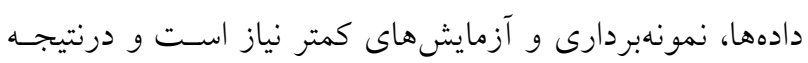

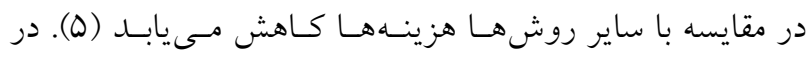

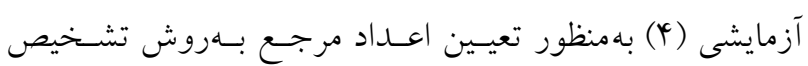

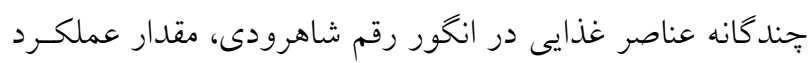
ع/T/N عملكرد مطلوب از باغهاى داراى عملكرد كم (نامطلوب) تعيين شد؛ بهطورى كه ب Y درصد از باغها در كروه باغهاى با عملكرد

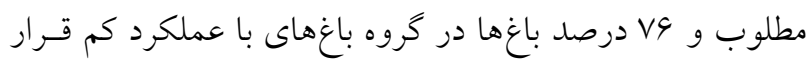

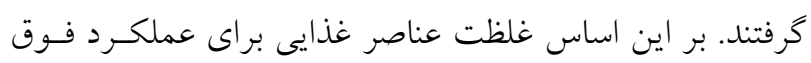

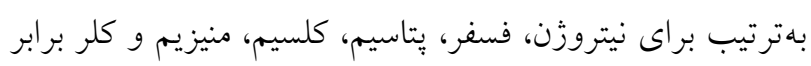

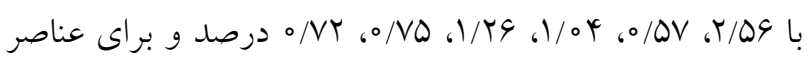

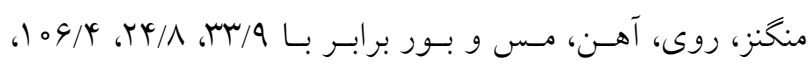

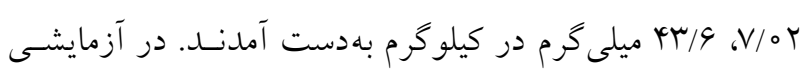

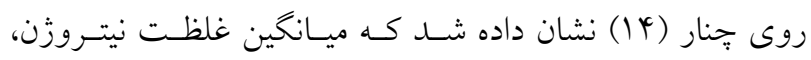

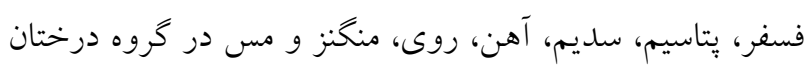

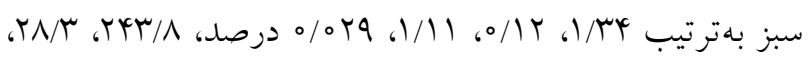

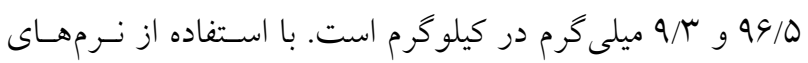

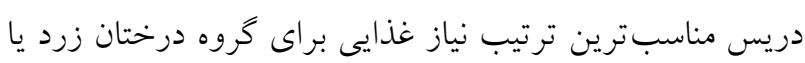

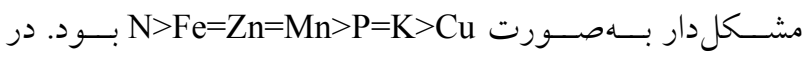

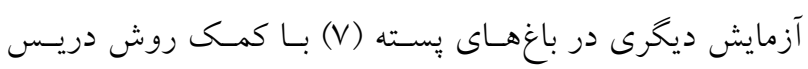

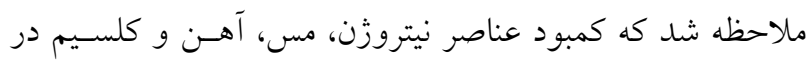

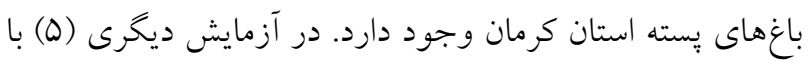
استفاده از مدل تابع تجمعى نسبت واريانس عناصر غـذايى و از 
مترى از سطح زمين و دور تا دور درخـتـت قـرار دانستند انجـام

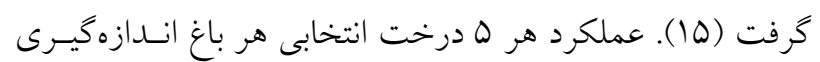

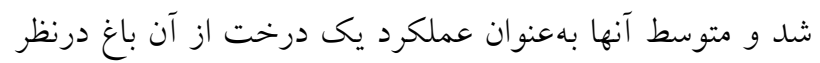

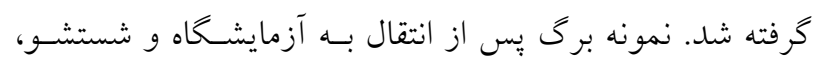

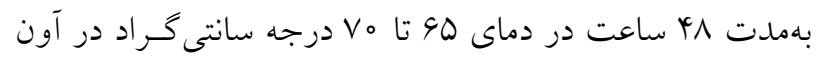

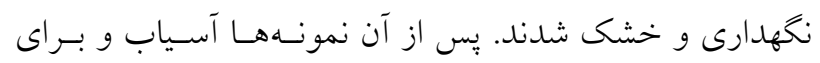
اندازهيرى عناصر غذايى مورد نظر مهيا شدند. عناصر نيتروزن،

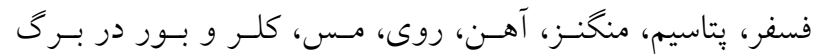

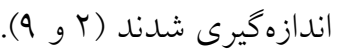

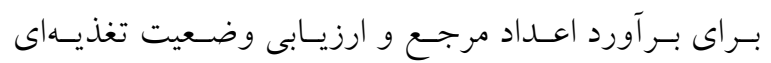

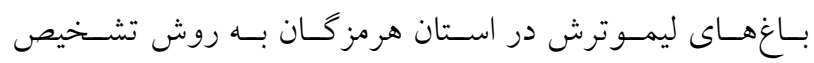

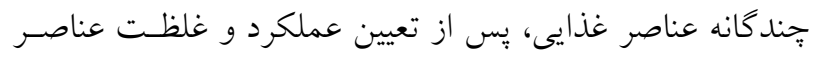

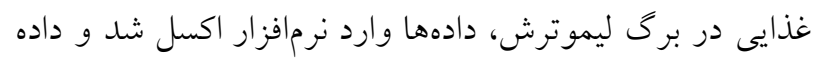

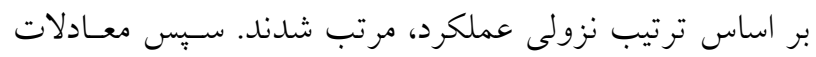

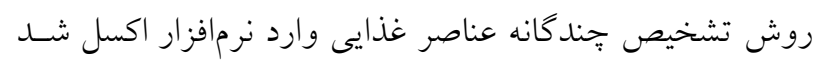

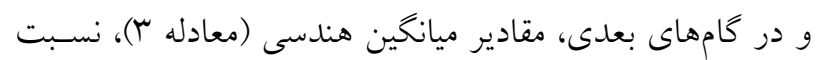

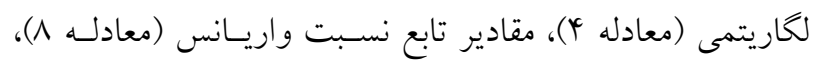

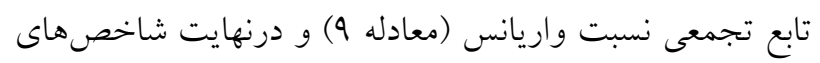
عناصر غذايى (معادله 9) و شاخص تعادل عناصر غذايى (معادله ) محاسبه شدند.

\section{تئورى روش جندگانه تشخيص عناصر غذايى}

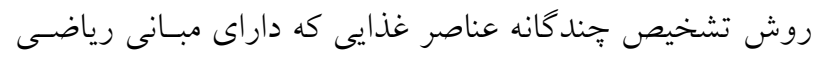

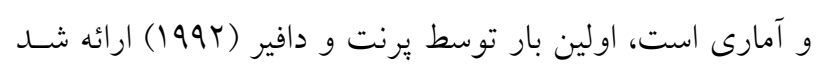

در اين روش كل تركيبات بافت كياهى شامل مواد معلنى و

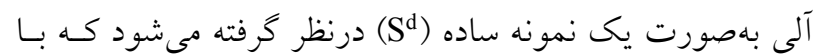

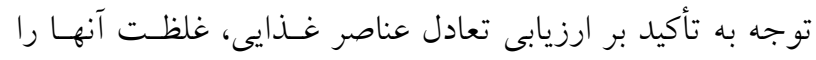

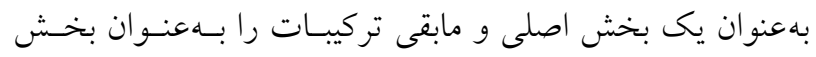
باقىمانده (R) فرض كرده كه بهشكل معادله ا قابل بيان است.

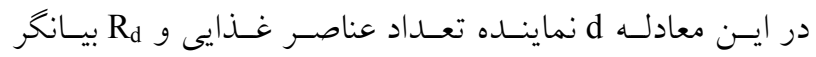
باقىمانده تركيبات كياهى است.
دارد. بديهى است تحت شرايط كاملاً مساعد مقـدار توليـــ ايـن

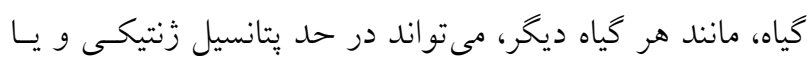

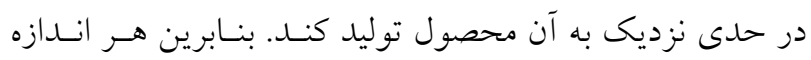

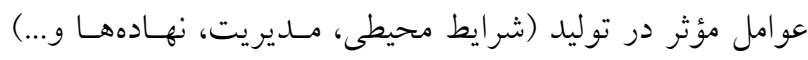

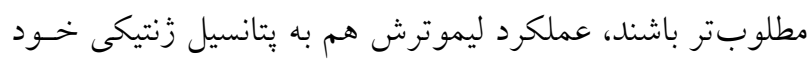

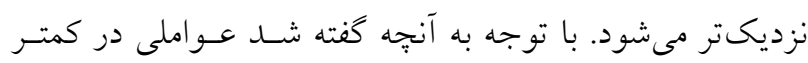

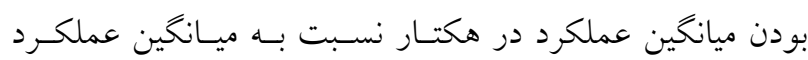

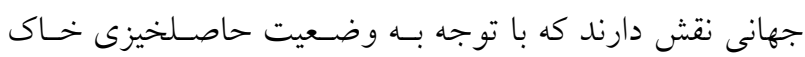

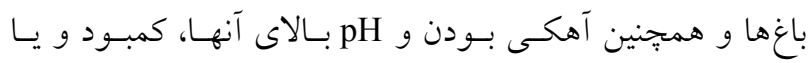

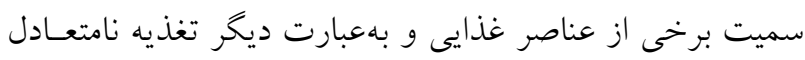

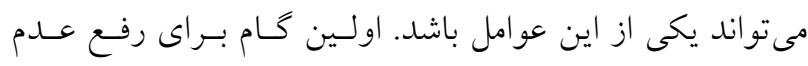

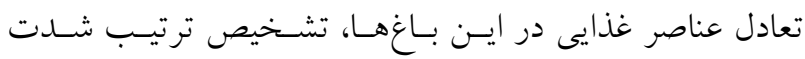

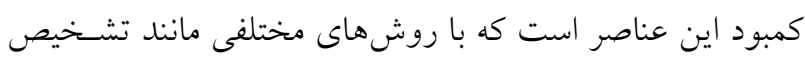
جندكانه عناصر غذايى، دريس، انحراف از درصد بهينـه و سـاير

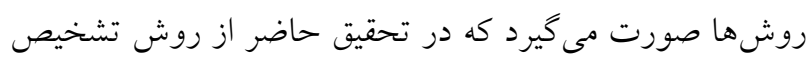

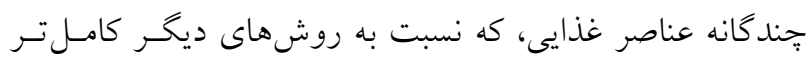

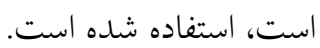

\section{روش تحقيق}

ابتدا، براى انجام اين تحقيق، سه منطقه مهم استان هرمزگـان (از

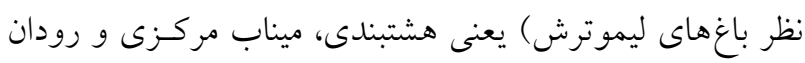

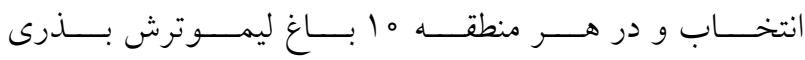
(Citrus aurantifolia)

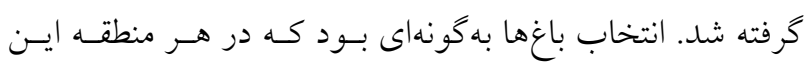

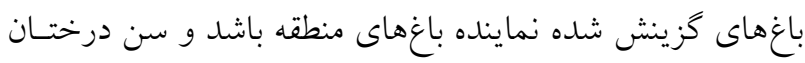

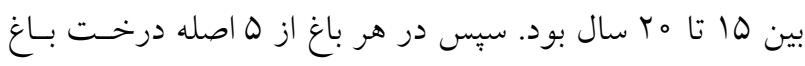

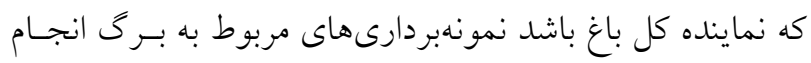

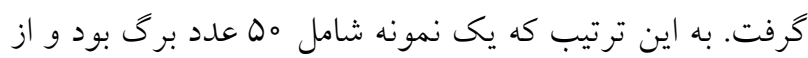

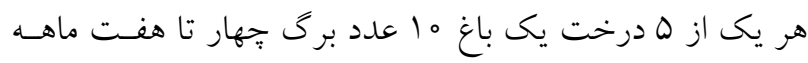

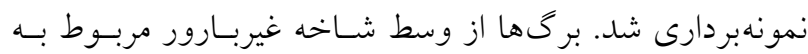

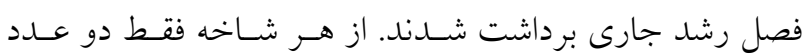

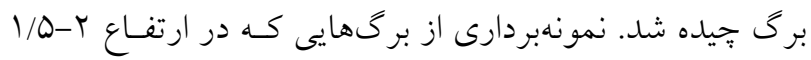


خو اهد شد (T) (I ). بنابر اين براى هـر نمونـه مشـخص كيـاهى از

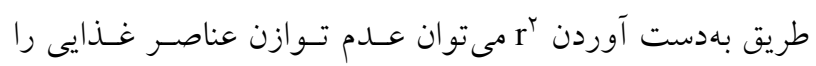

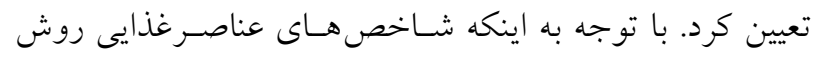

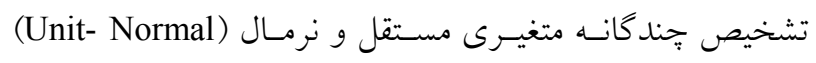

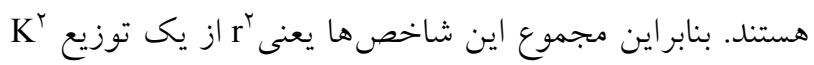

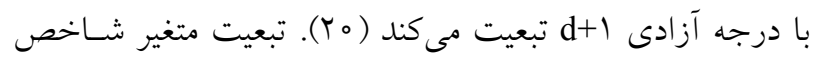

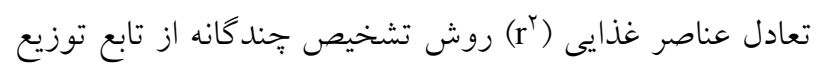
يكى مزيت اين روش در مقايسه بـا سـامانه دريسس (DRIS

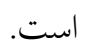

انتخاب جامعه با عملكرد مطلوب

براى اين منظور مى توان بـر اسـاس ترسيم تـابع تجمعسى بـين

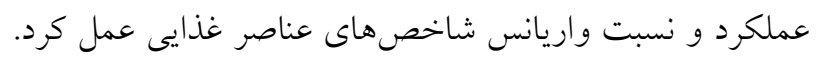

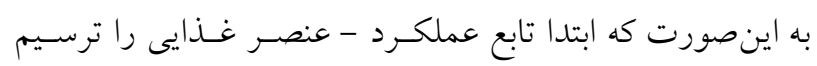

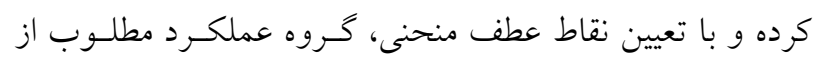

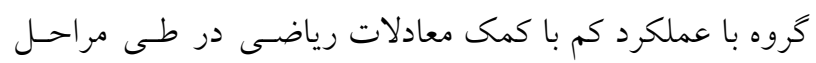
زير تفكيك شدند: - عملكردها از زياد به كم (ترتيب نزولى) مرتب شدندئد - نسبت لكاريتمى عناصر غذايى (vx) محاسبه شدند.

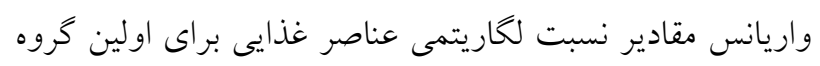

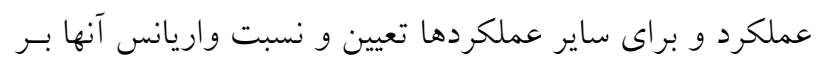

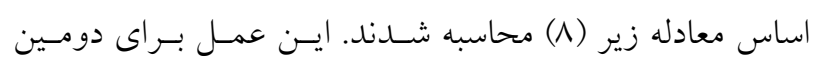
كروه عملكرد و سومين و... انجام شد:

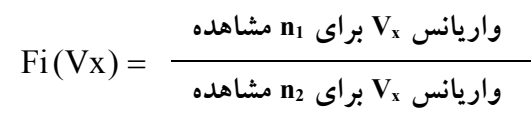

تابع تجمعى نسبت واريانس نيز بر اساس معادله (9) محاسبه شد: $\mathrm{F}_{\mathrm{i}}^{\mathrm{c}}=\frac{\sum_{\mathrm{i}=1}^{\mathrm{n}_{1}-1} \mathrm{f}_{\mathrm{i}}\left(\mathrm{V}_{\mathrm{x}}\right)}{\sum_{\mathrm{i}=1}^{\mathrm{n}_{1}-3} \mathrm{f}_{\mathrm{i}}\left(\mathrm{V}_{\mathrm{x}}\right)} \times 100$

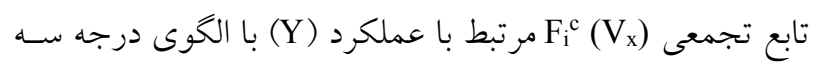
قابل نمايش است (معادله • (1): $\mathrm{F}_{\mathrm{i}}^{\mathrm{c}}\left(\mathrm{V}_{\mathrm{x}}\right)=\mathrm{a} \mathrm{Y}^{3}+\mathrm{b} \mathrm{Y}^{2}+\mathrm{cY}+\mathrm{d}$

$$
\begin{aligned}
& \mathrm{S}^{\mathrm{d}}= {\left[\left(\mathrm{N}, \mathrm{P}, \mathrm{K}, \ldots, \mathrm{R}_{\mathrm{d}}\right):\right.} \\
& \mathrm{N}>\circ, \mathrm{P}>\circ, \mathrm{K}>\circ, \ldots \\
&\left.\mathrm{R}_{\mathrm{d}}>\circ, \mathrm{N}+\mathrm{P}+\mathrm{K}+\ldots+\mathrm{R}_{\mathrm{d}}=100\right]
\end{aligned}
$$

با محاسبه Rd و داشتن غلظت عناصر غذايى، ميـانخين هندسى غلظت عناصر غذايى از معادله r محاسبه شد:

$\mathrm{G}=\left[\mathrm{N} \times \mathrm{P} \times \mathrm{K} \times \ldots . . \times \mathrm{R}_{\mathrm{d}}\right]^{1 / \mathrm{d}+1}$

يس از تعيين ميانخين هندسـى غلظـت عناصـر، نسـبت عناصـر غذايى به ميانخين هندسى با استفاده از معادله ب محاسبه شد: $\mathrm{V}_{\mathrm{N}}=\ln (\mathrm{N} / \mathrm{G}), \mathrm{V}_{\mathrm{P}}=\ln (\mathrm{P} / \mathrm{G})$,

$\mathrm{V}_{\mathrm{K}}=\ln (\mathrm{K} / \mathrm{G}), \mathrm{V}_{\mathrm{Rd}}=\ln \left(\mathrm{R}_{\mathrm{d}} / \mathrm{G}\right)$

$\mathrm{V}_{\mathrm{N}}+\mathrm{V}_{\mathrm{P}}+\mathrm{V}_{\mathrm{K}}+\ldots \ldots . . . \mathrm{V}_{\mathrm{Rd}}=。$

در اين خصوص بايستى اظهار كرد كه V براى عناصر در جامعه

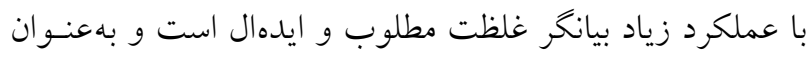

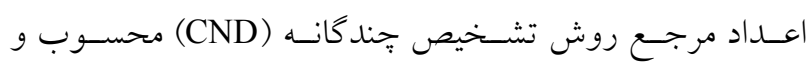

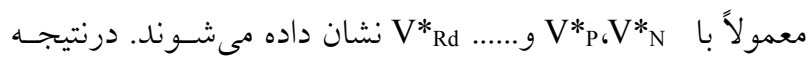

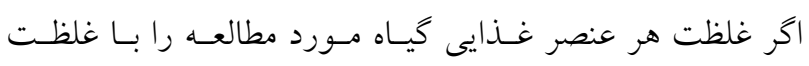

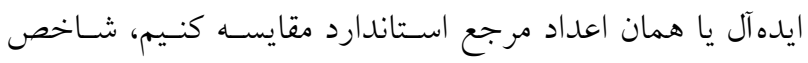

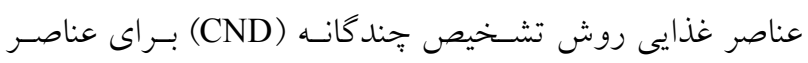
(X= N, P, K, ...R $\mathrm{Ix}=\frac{\mathrm{Vx}-\mathrm{V}^{*} \mathrm{x}}{\mathrm{SD}^{*} \mathrm{x}}$

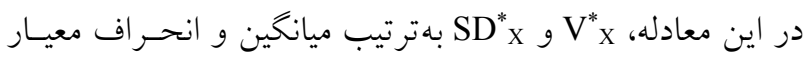

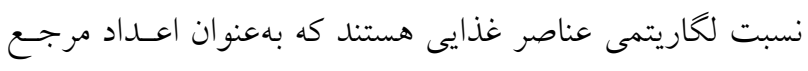

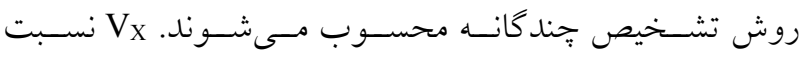

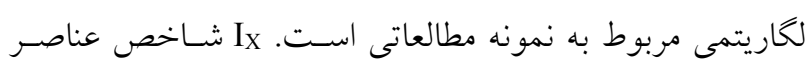
غذايى است. با داشتن شاخص عناصر غـذايى، شـاخص تعـادل عناصر غذايى از معادله 9 محاسبه شد: $r^{r}=I^{r} N+I^{r} P+I^{r} K+\ldots . I^{r} R_{d}$

شاخصهاى عناصر غذايى هميشه مىتواند اعداد صفر و بيشتر

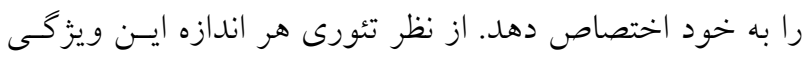

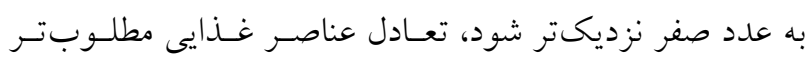


جدول ا. دامنه غلظت عناصر غذايى در برى درختان ليموترش هرمز كان

\begin{tabular}{|c|c|c|c|c|c|c|c|c|}
\hline بور & مس & روى & منخنز & آهن & 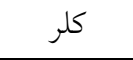 & ليتاسيم & فسفر & نيتروزن \\
\hline \multicolumn{5}{|c|}{ (ميلى گرم در كيلو گرم) } & \multicolumn{4}{|c|}{ (درصد) } \\
\hline $\mid r \Delta / r q-\varphi v N / / 0$ & $r / 90-9 r / 9 V$ & $r / 91-r / / 99$ & $V / r Y-1 N / \circ r$ & $৭ 9 / 9 \Delta-r \psi \psi / / V$ & $0 / 40-0 / 4 q$ & $1 / 0 \Delta-1 / N \Delta$ & O/YI-O/TQ & $r / r Q-r / 9 q$ \\
\hline
\end{tabular}

محاسبه شــ (جـــول r F $F_{i}^{c}\left(V_{R d}\right), F_{i}^{c}\left(V_{B}\right) ، F_{i}^{c}\left(V_{C u}\right)$ نقاط عطف منحنىهاى مربوط به معادلات جـدول ז، از طريـق

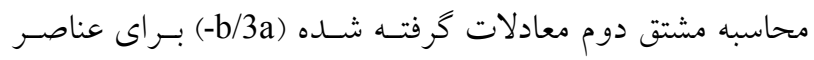

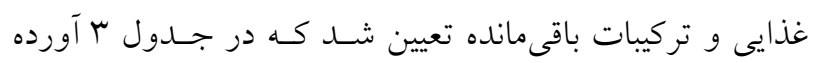

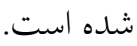
معادلات درجه سه بـراى كيلـه عناصـر معنسىدار و ضـريب

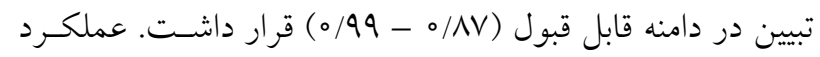

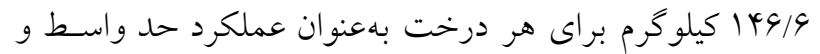

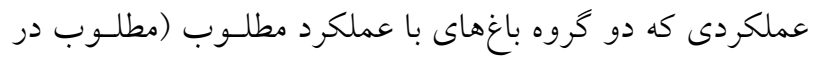

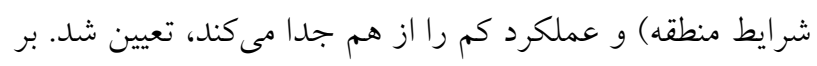

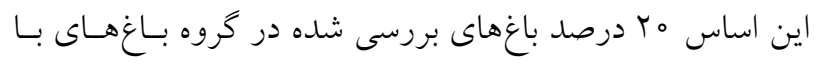

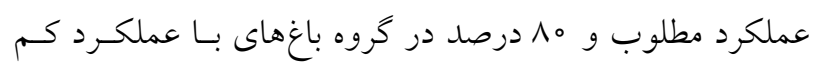
قرار گرفتند. از مقايسه هريك از مقادير جدول ؟ با مقدار عملكرد حد

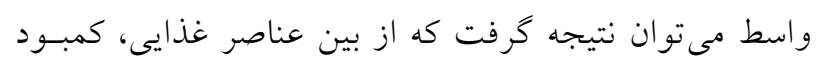

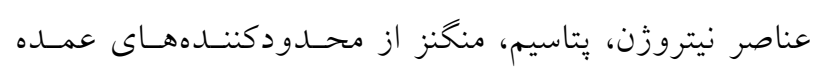

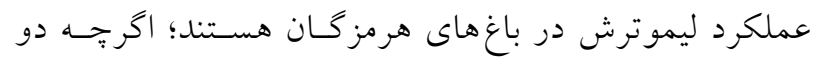

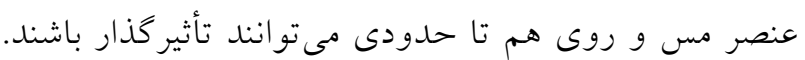

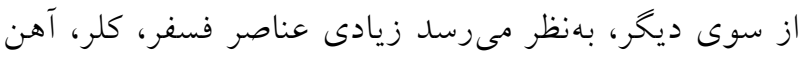

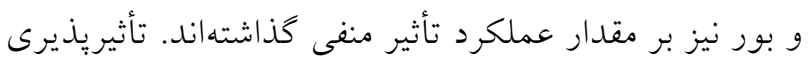

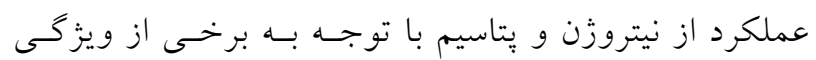

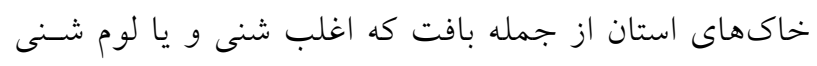

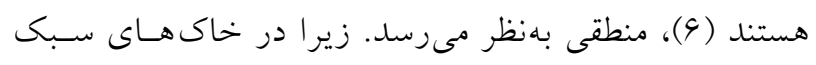

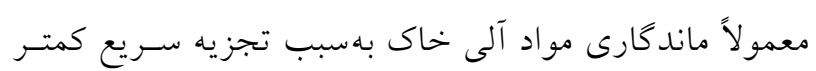

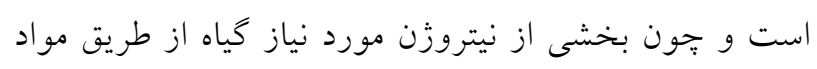

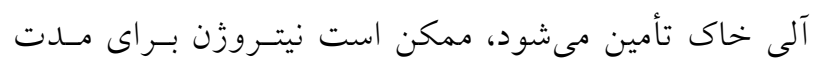

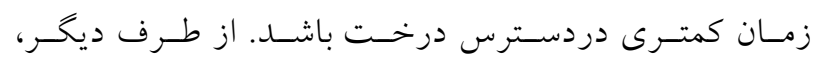

نقاط عطف منحنىهـا از طريـق محاسـبه مشـتق دوم معـادلات درجه سه محاسبه شد (معادلات Iا و Y I):

$\frac{\partial \mathrm{F}_{\mathrm{i}}^{\mathrm{c}}\left(\mathrm{V}_{\mathrm{x}}\right)}{\partial \mathrm{Y}}=3 \mathrm{a} \mathrm{Y}^{2}+2 \mathrm{bY}+\mathrm{c}$

$\frac{\partial^{2} \mathrm{~F}_{\mathrm{i}}^{\mathrm{c}}\left(\mathrm{V}_{\mathrm{x}}\right)}{\partial \mathrm{Y}^{2}}=6 \mathrm{aY}+2 \mathrm{~b}=0$

از حل معادله (Y I ) مقدار b/3a- بيانكر عملكرد حدواسـط بسين

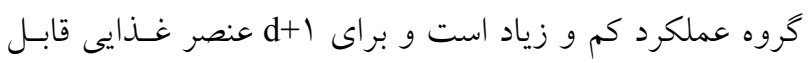
محاسبه شد. محاسبات و نمودارها با كمك نرمافزار اكسل انجام

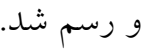

\section{نتايج و بحث}

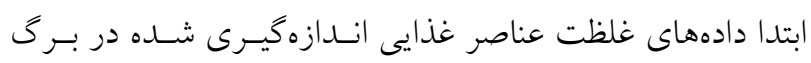

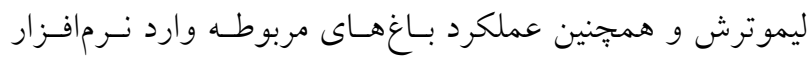

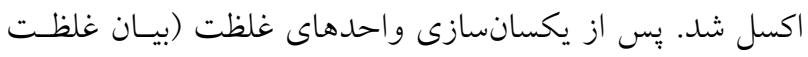

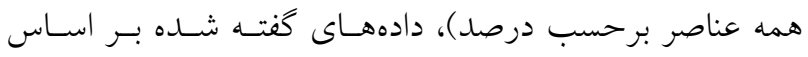

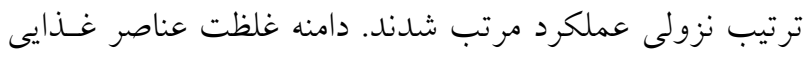

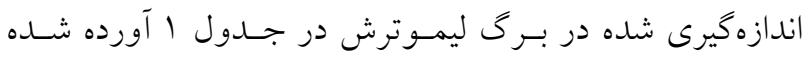

بهمنظور جداسازى باغهاى با عملكرد مطلوب از باغهاى بـا

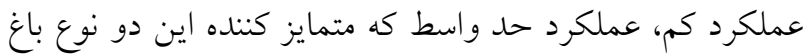
بود، محاسبه شد. بــراى محاسـبه عملكـــد حســ واسـط، مقـادير

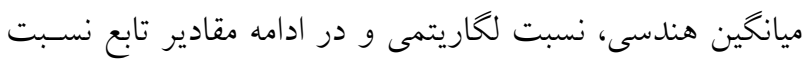
واريانس عناصر غذايى و درنهايت تابع تجمعى واريانس نسـبت

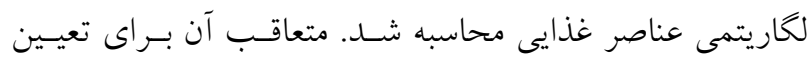
عملكرد حد واسط، ارتباط بين عملكرد ميوه و مقـادير تجمعى ، $F_{i}^{c}\left(V_{P}\right)$ ، Fi ، $\mathrm{F}_{\mathrm{i}}^{\mathrm{c}}\left(\mathrm{V}_{\mathrm{Zn}}\right) \quad \mathrm{F}_{\mathrm{i}}^{\mathrm{c}}\left(\mathrm{V}_{\mathrm{Mn}}\right) \quad \mathrm{F}_{\mathrm{i}}^{\mathrm{c}}\left(\mathrm{V}_{\mathrm{Fe}}\right) \quad \mathrm{F}_{\mathrm{i}}^{\mathrm{c}}\left(\mathrm{V}_{\mathrm{Cl}}\right) \quad \mathrm{F}_{\mathrm{i}}^{\mathrm{c}}\left(\mathrm{V}_{\mathrm{K}}\right)$ 
Fi (Vx) جدول Y. بر آورد عملكرد حد واسط (نقطه عطف منحنى) بر اساس روش توابع تجمعى واريانس نسبت لكاريتمى عناصر غذايى

\begin{tabular}{|c|c|c|c|}
\hline عملكرد حد واسط يا نقطه عطف منحنى & ضريب تبيين & معادلات & 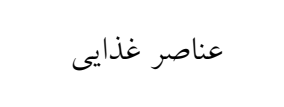 \\
\hline 110 &.$/ 94$ & $y=-0 / 000 r x^{r}+0 / 0991 x^{r}-11 / 999 x+r q 4 / r 1$ & نيتروزن (N) \\
\hline IVV & $\circ / 9 \mathrm{~V}$ & $y=-0 / 0001 x^{r}+0 / 0 \Delta r r x^{r}-V / 09 \Lambda x+r r q / r q$ & فسفر (P) \\
\hline מזו &.$/ 91$ & 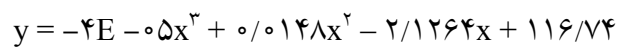 & يتاسيم (K) \\
\hline 194 & $\circ / 99$ & $y=\Lambda E-09 x^{r}+0 / 00 \varphi 9 x^{r}-r / \Lambda \Lambda \varphi \mid x+r 00 / 0 \Lambda$ & كلر (Cl) \\
\hline 101 & $\circ / 19$ & $y=-0 / 000 r x^{r}+0 / 09 \varphi q x^{r}-1 r / 1 r V x+r q V / I V$ & آهن (Fe) \\
\hline ITY & $\circ / 99$ & $y=-r E-0 \Delta x^{r}+0 / 0\left|\psi q x^{r}-r / r \wedge q V x+\right| \wedge q / q \varphi$ & منخَنز (Mn) \\
\hline 140 & $\circ / \wedge \vee$ & $y=-0 / 000 r x^{r}+0 / 1 r \circ \wedge x^{r}-10 / 90 \vee x+4 / V / r \varphi$ & روى (Zn) \\
\hline lk & $\circ / \wedge 9$ & $\mathrm{y}=-0 / 000 r \mathrm{x}^{r}+0 / 1 r \wedge 9 \mathrm{x}^{r}-10 / \wedge r 9 \mathrm{x}+9 r r / 4 \Delta$ & مس (Cu) (Cu) \\
\hline 190 &.$/ 91$ & $y=-r E-0 \Delta x^{r}+0 / 011 r x^{r}-r / r \Lambda 1 r x+19 \Lambda / 99$ & بور (B) - ت بو) \\
\hline 109 & $\circ / 91$ & $y=-0 / 000 r x^{r}+0 / 0 q \mu r x^{r}-\Lambda / r r r q x+r q r / \Lambda$ & تركيبات باقى مانده ( \\
\hline $149 / 9$ & - & - & ميانخين \\
\hline
\end{tabular}

جدول r. مقادير نقاط عطف (يا عملكرد بر حسب كيلوگرم بر درخت) براى هر كدام از عناصر غذايى مورد بررسى و تركيبات باقىمانده

\begin{tabular}{cccccccccc}
\hline $\mathrm{F}_{\mathrm{i}}^{\mathrm{c}}\left(\mathrm{V}_{\mathrm{Rd}}\right)$ & $\mathrm{F}_{\mathrm{i}}^{\mathrm{c}}\left(\mathrm{V}_{\mathrm{B}}\right)$ & $\mathrm{F}_{\mathrm{i}}^{\mathrm{c}}\left(\mathrm{V}_{\mathrm{Cu}}\right)$ & $\mathrm{F}_{\mathrm{i}}^{\mathrm{c}}\left(\mathrm{V}_{\mathrm{Zn}}\right)$ & $\mathrm{F}_{\mathrm{i}}^{\mathrm{c}}\left(\mathrm{V}_{\mathrm{Mn}}\right)$ & $\mathrm{F}_{\mathrm{i}}^{\mathrm{c}}\left(\mathrm{V}_{\mathrm{Fe}}\right)$ & $\mathrm{F}_{\mathrm{i}}^{\mathrm{c}}\left(\mathrm{V}_{\mathrm{Cl}}\right)$ & $\mathrm{F}_{\mathrm{i}}^{\mathrm{c}}\left(\mathrm{V}_{\mathrm{K}}\right)$ & $\mathrm{F}_{\mathrm{i}}^{\mathrm{c}}\left(\mathrm{V}_{\mathrm{P}}\right)$ & $\mathrm{F}_{\mathrm{i}}^{\mathrm{c}}\left(\mathrm{V}_{\mathrm{N}}\right)$ \\
\hline 109 & 190 & $1 \mathrm{rr}$ & 140 & $1 \mathrm{r}$ & $10 \Lambda$ & $19 r$ & $1 \mathrm{r}$ & $1 \mathrm{r}$ & 110 \\
\hline
\end{tabular}

رواج مصرف اين عناصر در بين كشـاورزان و همجنسين آهكى بودن و pH بالاى خاى بـاغهـاى مـورد بررسسى دور از انتظـار نيست. بنابراين، بهطور كلى، نيـاز بـه مصـرف ايـن عناصـر در باغهاى منطقه وجود دارد كه رابطه افزايش عملكـــد بـا كـاربرد اين عناصر (براى مثال منخنز) در شكل ا نشان داده شده اسـت. در مورد آهن، با توجه به اينكه در اين آزمايش مقدار آهن كـل، مله

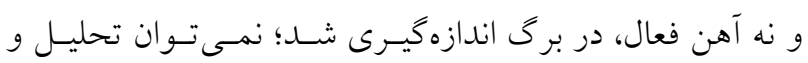
قضاوت صحيحى انجام داد. احتمالاً تـأثير منفسى عناصسر بـور و كلر بر عملكرد به غلظت بــش از انـدازه ايسن عناصـر در گيـاه مربوط باشد؛ زيرا بين غلظت اين عناصر و عملكرد درخت يك رابطه معكوس مشاهده شد (شـكل هـاى r و r). علـت زيـادى غلظت اين عناصر (كلر و بور) در درخت ليموترش، اغلـب، بـه كيفيت پايين آبهاى آبيارى منطقه برمى گردد كه داراى درجات

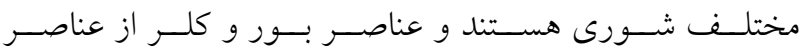
تشكيل دهنده شورى اين آب ها هستند (11). بـا بررسسى مقـدار برخى از عناصر اندازهيرى شده مانند بور در بــزوهش حاضـر،
سبك بودن بافت خاك سبب مى شود بخـش قابـل تـوجهى از

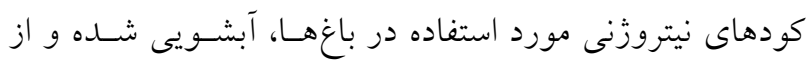
دسترس كياه خارج شوند؛ بهويزه اينكه در اغلب باغهاى مورد بررسى از سيستم آبيارى غرقابى استفاده مى شــ؛ درحسالى كـه

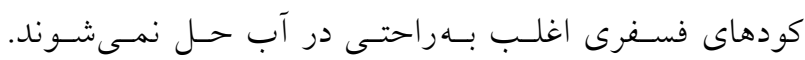
همجينين شنى بودن بافت خـاك سـبب شـده اسـت تـا مقـدار

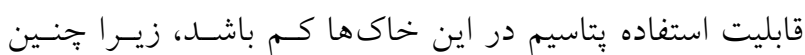
خـاكهــايى بـهـطـور ذاتـى از نظــر مقــار يتاسـيم وضـعيت رضايتبخشى ندارند (Y) با بررسى بيشـتر ملاحظـه شــ كـه ميـانخين يتاسـيم خـاى باغهـاى ليمـوترش در ســه منطقـه مينـاب، رودان و هشـتبندى

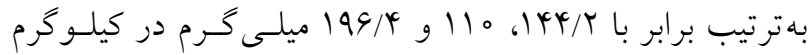
خاك بود كه در عمـق هب تــا ه9 سـانتى متـرى ايسـن مقـادير تـا حدودى كاهش بيدا كرده بودند. ايسن مقـدار از بتاسـيم در ايسن مناطق در دامنه يايين تا متوسط قرار مى گيرند (II).

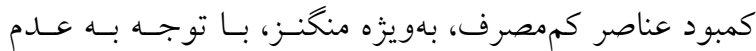




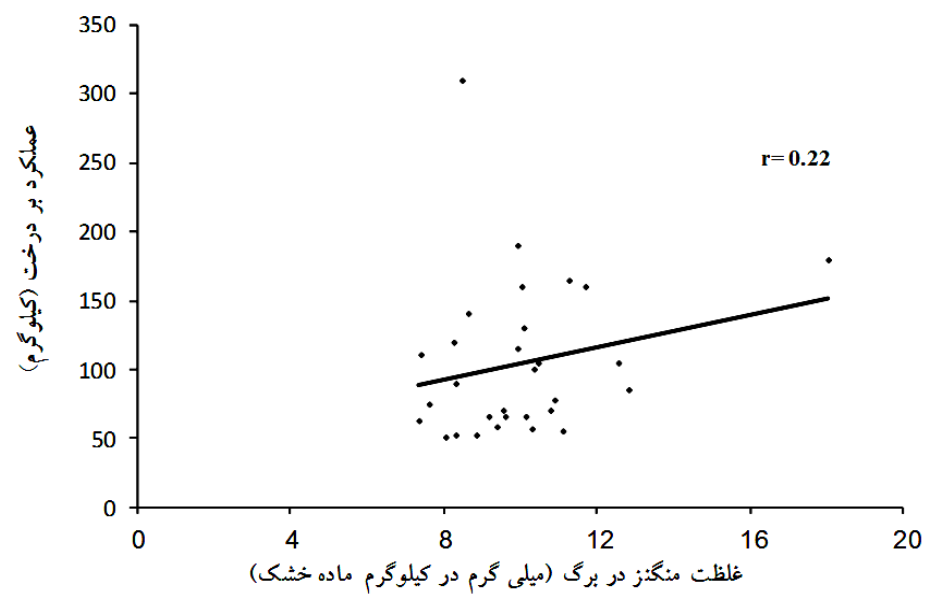

شكل 1. تأثير غلظت منكنز برگ بر عملكرد ليموترش در سالهاى باغى بهو و هو در هرمز كان

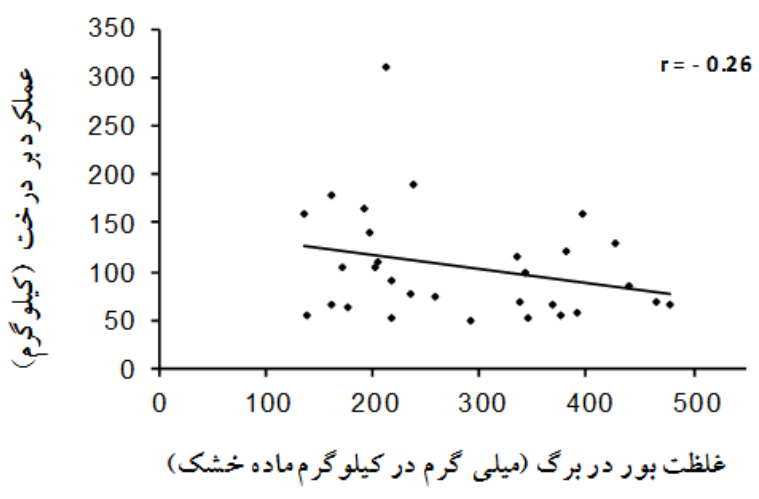

شكل r. تأثير منفى بور برگ بر عملكرد ليموترش در

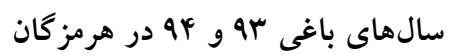

از سطح بحر انى بود. ميانخين غلظت كلر در محلول خاك بـراى

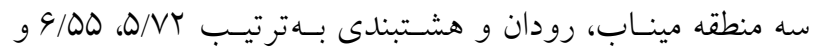

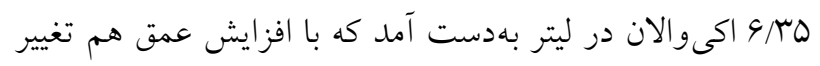

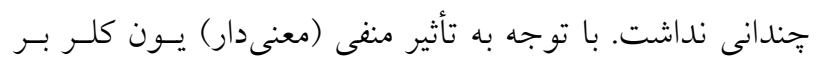

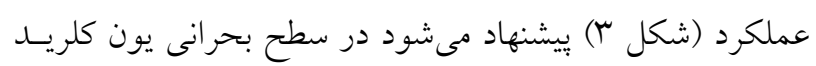

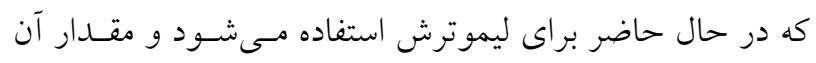

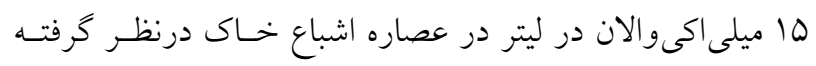

$$
\text { شده است (1) بازنخرى صورت كيرد. }
$$

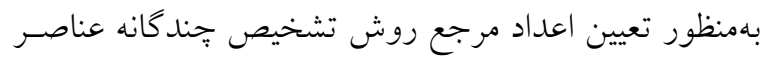

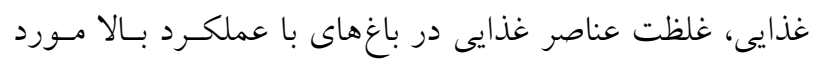

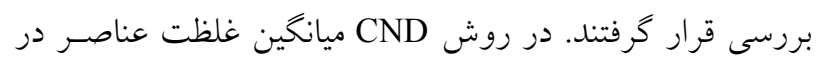

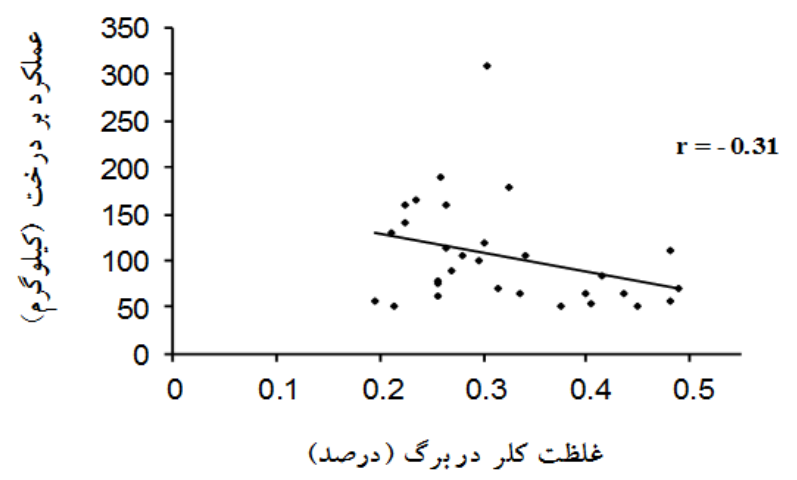

شكل r. تأثير منفى غلظت كلريد برگ بر عملكرد ليموترش در

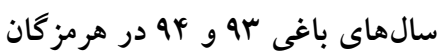

مشخص شد ميانگين غلظت عنصر مذكور در آب آبيارى بـراى

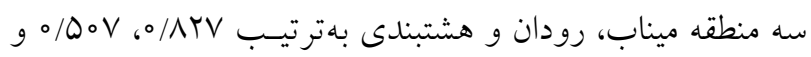

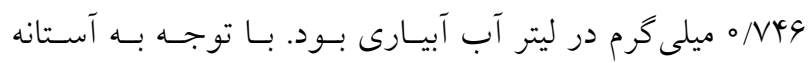

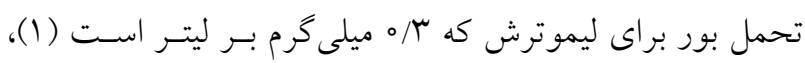

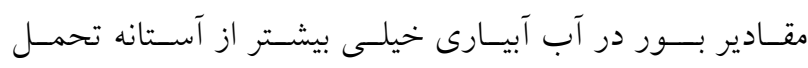

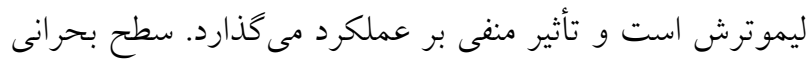

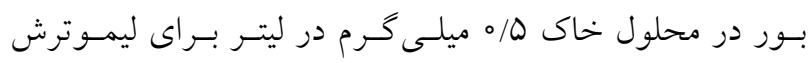

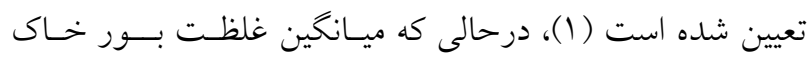

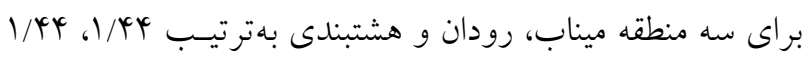

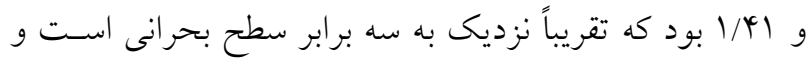

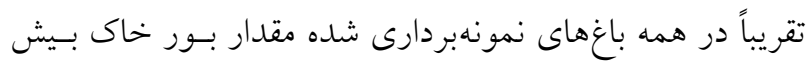


جدول f. اعداد مرجع روش تشخيص جندگانه عناصر غذايى (نرمهاى CND) و ميانگين غلظت بهينه عناصر غذايى در باغهاى

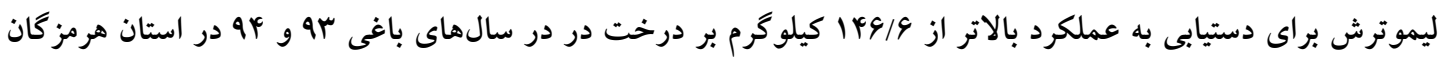

\begin{tabular}{|c|c|c|c|c|c|}
\hline \multirow{2}{*}{ انحراف معيار } & ميانكين بهينه عناصر غذايى & \multirow{2}{*}{ عناصر غذايى } & \multirow{2}{*}{ انحراف معيار } & \multirow{2}{*}{ ميانخين } & \multirow{2}{*}{ نرمهاى CND } \\
\hline & (درصدد) & & & & \\
\hline$\circ / T Q .99$ & $r / M$ & $\mathrm{~N}$ &.$/ 0 V 9$ & $r / 9 \Lambda$ & $\mathrm{V}_{\mathrm{N}}^{*}$ \\
\hline ०/ODYGI & $0 / T \Lambda$ & $\mathrm{P}$ & o/NA & $1 / \pi r$ & $\mathrm{~V}_{\mathrm{P}}^{*}$ \\
\hline.$/ \pi 91 V \pi$ & $1 / \pi 1$ & $\mathrm{~K}$ &.$/ 190$ & T/AV & $\mathrm{V}^{*}{ }_{\mathrm{K}}$ \\
\hline \multirow[t]{2}{*}{$\circ / \% 4 \circ 4$} & $\circ / T V$ & $\mathrm{Cl}$ & $0 / 1 Y 9$ & $1 / \pi \circ$ & $\mathrm{V}_{\mathrm{Cl}}^{*}$ \\
\hline & $\left(\mathrm{mg} \mathrm{kg}^{-1}\right)$ & & & & \\
\hline$I N / V$ & TYT/YG & $\mathrm{Fe}$ &.$/ 09 V$ & $-1 / 19$ & $\mathrm{~V}^{*} \mathrm{Fe}$ \\
\hline$r / \varphi$ & $11 / \Delta V$ & Mn & $0 / 491$ & $-\varphi / I V$ & $\mathrm{~V}^{*}{ }_{\mathrm{Mn}}$ \\
\hline$\circ / 4$ & $r / g r$ & $\mathrm{Zn}$ & $\circ \% \vee r$ & $-Q / 09$ & $\mathrm{~V}^{*} \mathrm{Zn}$ \\
\hline $0 / 4$ & $9 / 9 \mathrm{~V}$ & $\mathrm{Cu}$ &.$/ 009$ & $-4 / 99$ & $\mathrm{~V}^{*} \mathrm{Cu}$ \\
\hline \multirow[t]{3}{*}{$9 Y / 1$} & TYY/A。 & B & $0 / r \wedge r$ & $-1 / T 4$ & $\mathrm{~V}^{*}{ }_{\mathrm{B}}$ \\
\hline & & & $\circ / \%$ భ & $\mathrm{V} / \mathrm{\Lambda}$ & $\mathrm{V}^{*} \mathrm{Rd}$ \\
\hline & & & & $\circ / 0 \circ$ & $\sum \mathrm{V}$ \\
\hline
\end{tabular}

باغهاى مورد مطالعه متفاوت هستند (جدول () و در تعداد قابل

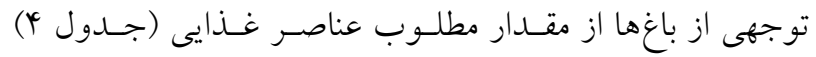

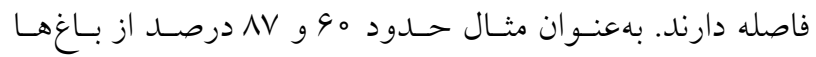

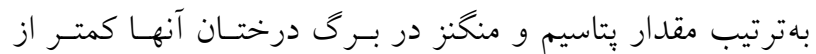
مقدار بهينه (جدول \&) است؛ درحالى كـه بـــاى عناصـر كلـر و و

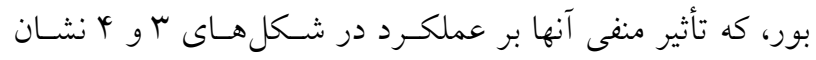

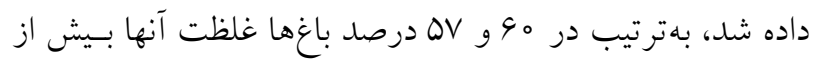

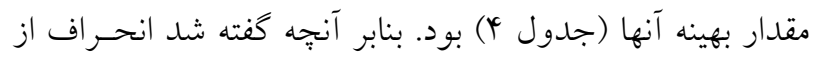
غلظت بهينه عناصر در برى درختان بـاغهـاى ليمـوترش مـورد

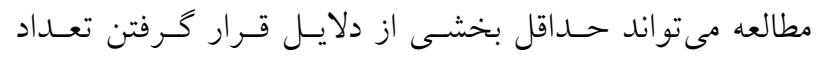

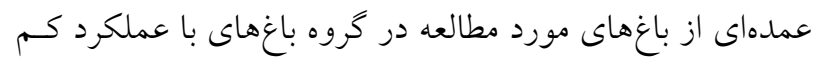
باشد. شاخص تعـادل عناصـر غــايى در روش جندئانه عناصـر غذايى براى باغهاى ليموترش با عملكرد بالا براى همـه عناصـر

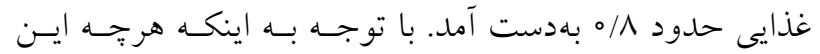
شاخص به صفر نزديكتر باشد تعادل بهترى بين عناصر غـذايى
برى درختان باغهاى با عملكرد بالا بهعنوان غلظت بهينه عناصر

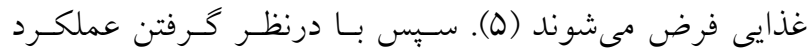

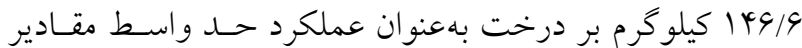

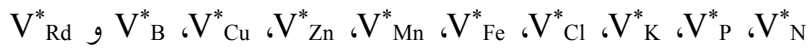
بهنوان اعداد مرجع تشخيص عناصر جندكانـه عناصـر غـذايى

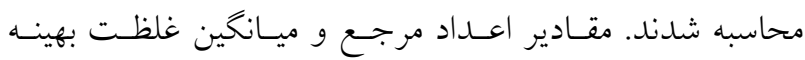
عناصر غذايى در جدول ץ ب نشان داده شدهاند.

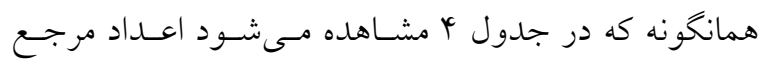

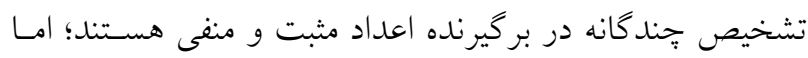

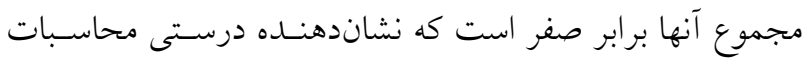

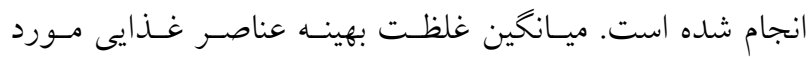

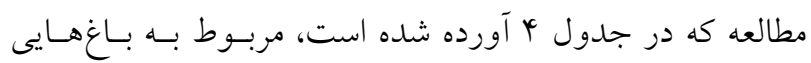

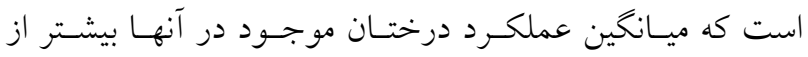

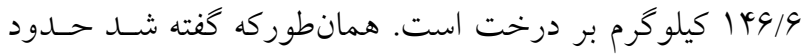
م1 درصد از باغهاى ليموترش در گروه باغهاى با عملكرد كـم قرار كرفتند؛ از طرفى، غلظت عناصر غذايى مورد بررسى نيز در 


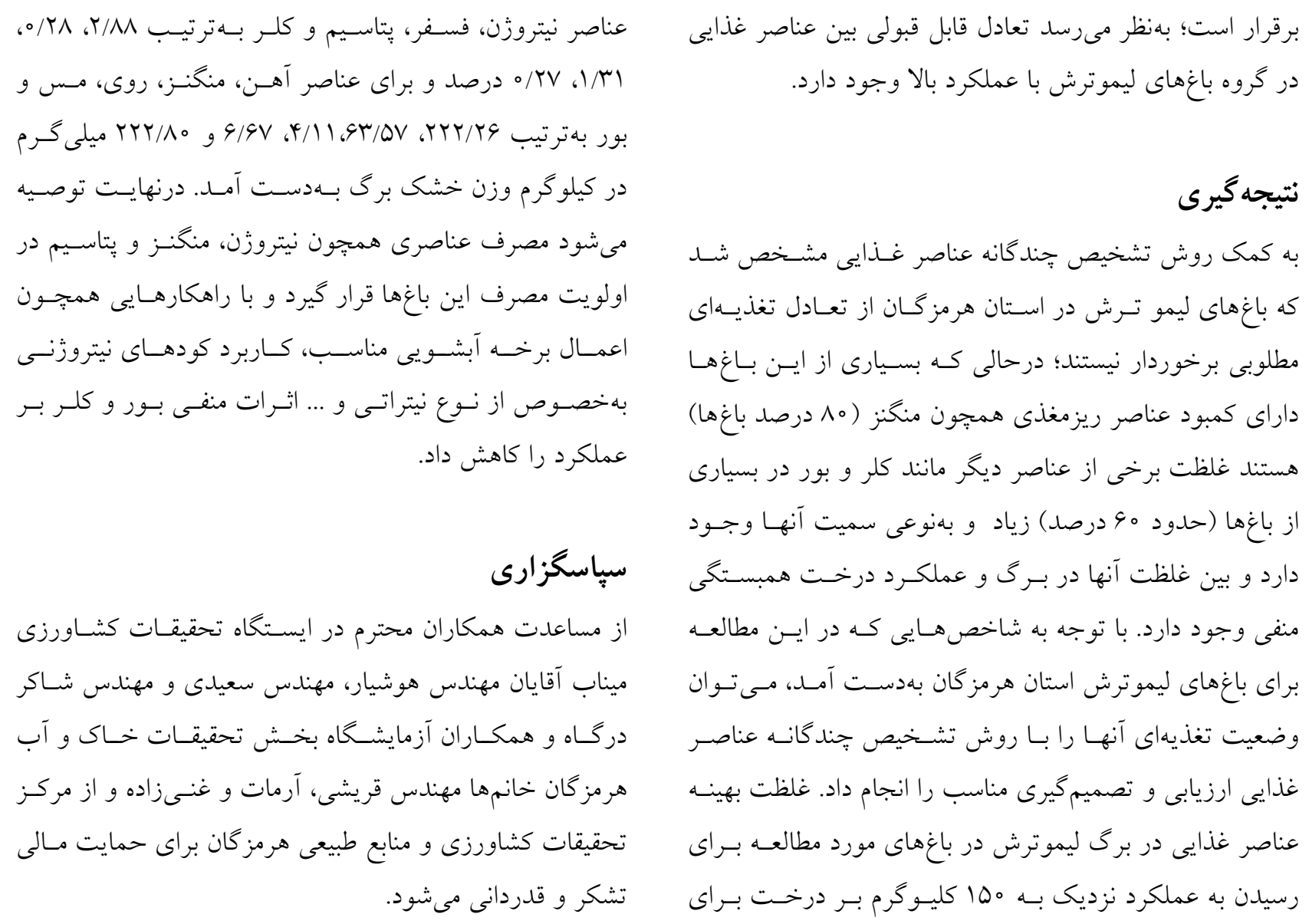

1- Abtahi, A. 1992. Plant Tolerance to Salinity. Technical Publication No. 16. Soil Department, Faculty of Agriculture, University of Shiraz, Shiraz, Iran. (In Farsi)

2- Alaee Yazdi, F. and G. R. Firoozabadi. 2001. Interpretation of Test Results and Soil Fertility Management. Yazd Agricultural Organization Publication, Yazd. (In Farsi).

3- Basirat, M., A. Akhyani and A. M. Daryashenas. 2016. Estimating sufficiency norms in compositional nutrient diagnosis (CND) method for Shahroudi grape. Soil Researches Journal 30(1): 1-12. (In Farsi).

4- Chakerolhosseini, M. R., R. Khorassani, A. Fotovat and M. Basirat. 2016. Determination of norms and limitation of nutrients for orange by the compositional nutrient diagnosis method. Journal. of Soil Management and Sustainable Production 6(3): 161-172. (In Farsi).

5- Daryashenas, A. M. and H. Rezaee. 2010. Determination of DRIS reference norms for autumn sugar beet in Khuzestan province. Suger Beet Journal 26(2): 185-204. (In Farsi).

6- Daryashenas, A. M. and K. Saghfi. 2010. Determination and evaluation of nutrient standards by CND method for optimization of fertilizer recommendations in sugar beet. Proceeding of the 1st Iranian Fertilizer Challenges Congress: Half a Century of the Fertilizer Consumption, Tehran, Iran, 1-2 March. (In Farsi).

7- Daryashenas, A. M. and K. Saghfi. 2011. Multiple nutritional determination (CND) for sugar beet. Soil Researches Journal 25(1): 1-12. (In Farsi).

8- Dordipour, E., P. Emami and A. M. Daryashenas. 2013. Evaluation of nutritional balance through DRIS method in peach orchards of Golestan Province. Journal of Water and Soil Conservation 20(2): 1-18. (In Farsi).

9- Emami, A. 1996. Descriptions of Plant Decomposition Methods (first volume). Agricultural Research, Education and Extentional Organization, Tehran. (In Farsi).

10-Heshmati Rafsanjani, M. and M. J. Malakooti. 1998. Determination of primary DRIS norm for nine elements in pistachio. Iranian Journal of Agriculture Science 2: 342-351. (In Farsi). 
11-Hosseini, Y. 2010. Fertilizer application in agricultural lands of Hormozgan province. Proceeding of $1^{\text {st }}$ Iranian Fertilizer Challenges Congress: Half a Century of the Fertilizer Consumption, Tehran, Iran. 1-2 March. (In Farsi).

12-Khiari, L., L. E. Parent and N. Tremblay. 2001c. Selecting the high-yield subpopulation for diagnosing nutrient imbalance in crops. Agronomy Journal 93: 802-808.

13-Legezian, A., V. Fiazi Asl, A. Tehrani Far, A. Halaj Nia, H. Rahmani, P. Pakdl, S. H. Mohseni and A. Talebi. 2012. Determination of DRIS norms and assessment of nutritional value of plane trees (Platanus Sp.) in Mashhad. Journal of Horticultural Science 1: 35-44. (In Farsi).

14-Mahini Fard, M. S. 2011. Evaluation of greenhouse cucumber nutritional status by deviation from optimal percentage (DOP) and multiple nutritional determination (CND) in greenhouses of Yazd province (MSc Thesis). Shahid Bahonar University, Kerman, Iran. (In Farsi).

15-Malakooti, M. J. and M. Nafisi. 1988. Use of Fertilizer in Irrigated and Rainfed Lands. Tarbiat Modarres University Publicattion, Tehran. (In Farsi).

16-Malakooti, M. J. and S. J. Tabatabaee. 1999. Proper Nutrition of Fruit Trees. Agricultural Education Pulication, Karaj. (In Farsi).

17-Montanes, L., L. Heras, J. Abadia and M. Sans. 1993. Plant analysis interpretation based on a new index: Deviation from optimum percentage (DOP). Journal of Plant Nutrition 16: 1289-1308.

18-Parent, L. E. and M. Dafir. 1992. A theoretical concept of compositional nutrient diagnosis. Journal of American Society for Horticultural Science 117: 239-242.

19-Ross, S. M. 1987. Introduction to Probability and Statistics for Engineers and Scientists. John Wiley \& Sons, New York.

20-Sajadi, A. S. 1996. Determination of the level of nutrients in sugar beet using the DRIS method (Final Report). Soil and Water Reseach Institute, Tehran. (In Farsi).

21-Samadi, A. and A. Majidi. 2010. Determination of reference numbers of the DRIS method and its comparison with the method of deviation from the optimal percentage (DROP) in white vine. Soil Researches Journal 24(2): 89-105. (In Farsi). 


\title{
Evaluation of Nutritional Status of Lime Orchards in Hormozgan Province of Iran using Compositional Nutrient Diagnosis Method
}

\author{
Y. Hosseini ${ }^{1 *}$, J. Saleh ${ }^{1}$ and M. R. Chakerolhosseini ${ }^{2}$
}

(Received: July 16-2018; Accepted: September 17-2019)

\begin{abstract}
Knowing the trees nutritional status is necessary for achieving balanced fertilization in orchards. One approach for determining the nutritional status of orchards is the compositional nutrient diagnosis method. In the present research this method was performed to evaluate the nutritional status of three important areas of lime cultivation in Hormozgan province, south of Iran, during 2014 and 2015. Comparison between the obtained results and standard nutrient concentrations in lime revealed that nitrogen, potassium, and manganese deficiency were the most limiting factors for lime production in Hormozgan lime orchards. Moreover, excess phosphorus, chlorine, iron, and boron showed negative effect on the fruit yield of lime. The optimum concentrations of nitrogen, phosphorus, potassium, and chlorine in the lime leaves in the studied orchards for achieving $150 \mathrm{~kg}$ fruit per tree were 2.88, $0.28,1.31,0.27 \%$ and those of iron, manganese, zinc, copper and boron were $222.26,11.57,4.63,6.67$, and $222.80 \mathrm{mg} / \mathrm{kg} \mathrm{DW}$, respectively. Therefore, it is recommended that using nutrients such as nitrogen, manganese and potassium must be given a priority in these orchards. Furthermore, some approaches like leaching fraction and supplying $\mathrm{N}^{-\mathrm{NO}_{3}}$ fertilizers should be utilized to mitigate the negative effects of boron and chlorine on the plant growth and yield.
\end{abstract}

Keywords: Citrus, CND method, Nutritional balance, Yield.

1. Faculty member of Soil and Water Research Department, Hormozgan Agricultural and Natural Resources Research and Education Center, Agricultural Research, Education and Extension Organization (AREEO), Bandar Abbas, Iran.

2. Faculty member of Horticulture Crops Research Department, Kohgiluyeh and Boyerahmad Agricultural and Natural Resources Research and Education Center, Agricultural Research, Education and Extension Organization (AREEO), Yasooj, Iran.

*: Corresponding Author, Email: yaaghoob.hosseini@yahoo.com 